\title{
How to deal with a clustering effect in the assessment of a hand hygiene improvement strategy implemented worldwide?
}

\author{
A Gayet-Ageron ${ }^{1 *}$, B Allegranzi ${ }^{2}, \mathrm{H}$ Attar $^{2}$, D Pittet $^{1}$ \\ From International Conference on Prevention \& Infection Control (ICPIC 2011) \\ Geneva, Switzerland. 29 June - 2 July 2011
}

\section{Introduction / objectives}

Hand hygiene $(\mathrm{HH})$ is a key measure to prevent healthcare-associated infections. Between 2006 and 2008, the WHO conducted pilot testing of the implementation of a multimodal $\mathrm{HH}$ improvement strategy in six sites worldwide. Collected data presented several aspects of complexity and levels of clustering that needed to be taken into account in the analysis. We describe a statistical approach aimed at minimizing potential bias arising from such complex datasets.

\section{Methods}

Through a before/after observational study, $\mathrm{HH}$ compliance was assessed in several wards ofdifferent hospitals in five countries from April 2006 to December 2008 using a validated method. The $\mathrm{HH}$ opportunity was the unit of analysis; data on $\mathrm{HH}$ indications and actions, observed professional categories, and day of the week observed were available. Simple logistic regression and mixed models using a nested clustering effect (hospital Iward \session) were used to assess the effect of the WHO strategy.

\section{Results}

A total of $45420 \mathrm{HH}$ opportunities were collected during 3613 sessions in 94 wards inin 43 hospitals from six pilot sites. Using a logistic regression model with fixed effects only, the crude odds for $\mathrm{HH}$ compliance after the intervention were 1.71 (95\% CI: 1.65-1.78) and the adjusted odds, 1.80 (95\% CI: 1.73-1.88). With a mixed model, the crude odds for $\mathrm{HH}$ compliance after

${ }^{1}$ Infection Control Programme, Universiy Hospitals of Geneva, Geneva, Switzerland

Full list of author information is available at the end of the article intervention were 1.99 (95\% CI: 1.86-2.14) and 2.13 (95\% CI: 1.97-2.29) after adjustment.

\section{Conclusion}

The effect of the strategy implementation may be underestimated if the correlation existing between data is not taken into account. A generalized linear mixed model using a nested clustering effect may be a solution to deal with correlated data, but as paired data are lacking, all correlations cannot be taken into account.

\section{Disclosure of interest}

None declared.

\section{Author details}

'Infection Control Programme, Universiy Hospitals of Geneva, Geneva, Switzerland. ${ }^{2}$ World Health Organization, Geneva, Switzerland.

Published: 29 June 2011

\begin{tabular}{l} 
doi:10.1186/1753-6561-5-S6-O71 \\
Cite this article as: Gayet-Ageron et al: How to deal with a clustering \\
effect in the assessment of a hand hygiene improvement strategy \\
implemented worldwide? BMC Proceedings 2011 5(Suppl 6):O71. \\
\hline Stbmity yotrrnext mantreript to BioNMed Centrat \\
and take full advantage of: \\
- Convenient online submission \\
- Thorough peer review \\
- No space constraints or color figure charges \\
- Immediate publication on acceptance \\
- Inclusion in PubMed, CAS, Scopus and Google Scholar \\
- Research which is freely available for redistribution \\
Submit your manuscript at \\
www.biomedcentral.com/submit
\end{tabular}

